\title{
Three-dimensional analysis of enamel surface alteration resulting from orthodontic clean-up -comparison of three different tools
}

\author{
Joanna Janiszewska-Olszowska ${ }^{1 *}$, Katarzyna Tandecka², Tomasz Szatkiewicz², Piotr Stępień ${ }^{3}$
} Katarzyna Sporniak-Tutak ${ }^{4}$ and Katarzyna Grocholewicz ${ }^{1}$

\begin{abstract}
Background: The present study aimed at 3D analysis of adhesive remnants and enamel loss following the debonding of orthodontic molar tubes and orthodontic clean-up to assess the effectiveness and safety of One-Step Finisher and Polisher and Adhesive Residue Remover in comparison to tungsten carbide bur.

Materials and methods: Thirty human molars were bonded with chemical-cure orthodontic adhesive (Unite, 3M, USA), stored $24 \mathrm{~h}$ in $0.9 \%$ saline solution, debonded and cleaned using three methods (Three groups of ten): tungsten carbide bur (Dentaurum, Pforzheim, Germany), one-step finisher and polisher (One gloss, Shofu Dental, Kyoto, Japan) and Adhesive Residue Remover (Dentaurum, Pforzheim, Germany). Direct 3D scanning in blue-light technology to the nearest $2 \mu \mathrm{m}$ was performed before etching and after adhesive removal. Adhesive remnant height and volume as well as enamel loss depth and volume were calculated.

An index of effectiveness and safety was proposed and calculated for every tool; adhesive remnant volume and duplicated enamel lost volume were divided by a sum of multiplicands. Comparisons using parametric ANOVA or nonparametric ANOVA rank Kruskal-Wallis tests were used to compare between tools for adhesive remnant height and volume, enamel loss depth and volume as well as for the proposed index.
\end{abstract}

Results: No statistically significant differences in the volume $(p=0.35)$ or mean height $(p=0.24)$ of adhesive remnants were found (ANOVA rank Kruskal-Wallis test) between the groups of teeth cleaned using different tools. Mean volume of enamel loss was $2.159 \mathrm{~mm}^{3}$ for tungsten carbide bur, $1.366 \mathrm{~mm}^{3}$ for Shofu One Gloss and $0.659 \mathrm{~mm}^{3}$ for Adhesive Residue Remover - $(F=2.816, p=0.0078$ ). A comparison of the proposed new index between tools revealed highly statistically significant differences $(p=0.0081)$, supporting the best value for Adhesive Residue Remover and the worst - for tungsten carbide bur.

Conclusions: The evaluated tools were all characterized by similar effectiveness. The most destructive tool with regards to enamel was the tungsten carbide bur, and the least was Adhesive Residue Removal.

Keywords: Orthodontic clean-up, Orthodontic debonding, Residual adhesive removal, Enamel damage, Adhesive remnants

\footnotetext{
* Correspondence: jjo@pum.edu.pl

${ }^{1}$ Department of General Dentistry Pomeranian Medical, University of

Szczecin, Al. Powstancow Wlkp. 72, 70-111 Szczecin, Poland

Full list of author information is available at the end of the article
} to the Creative Commons license, and indicate if changes were made. The Creative Commons Public Domain Dedication waiver (http://creativecommons.org/publicdomain/zero/1.0/) applies to the data made available in this article, unless otherwise stated. 


\section{Background}

Orthodontic adhesive removal can be performed with different tools, including: hand instruments (scalers, pliers) and rotary instruments: sandpaper discs $[1,2]$, diamond burs [3], stainless steel burs [3], rubbers [4], tungsten carbide burs [1-6] and fiber-reinforced composite burs [7]. Kinetic removal of adhesive remnants by intraoral sandblasting has been described by Kim et al. [8] and ultrasonic clean-up - by Hosein et al. [9] as well as by Ireland et al. [10].

The most popular tools are tungsten carbide burs, which are rapid and more effective in relation to adhesive removal than Sof-Lex discs, ultrasonic tools, hand instruments, rubbers or composite burs. However, they remove a substantial layer of enamel and roughen its surface, thus should be followed by polishing [11].

No studies have been found that assess resin remnants or enamel loss following adhesive rest removal with a one step polisher and finisher or with Adhesive Residue Remover.

Iatrogenic enamel damage has been subjectively assessed under a scanning electron microscope (SEM) $[1,2,12-16]$. Numerous authors have used different indexes to rate enamel surface under SEM [17-23]. Enamel roughness after orthodontic clean-up has been measured using contact profilometry [24-26], a noncontact white-light 3D profilometry [27] or atomic force microscopy [7].

The first measurements of enamel loss were performed referring to the depth of a reference hole [28] or to a recessed steel marker [29]. Later, measurements were made using a profile projector [30], a null-point contact stylus system [31], Planer Surfometer [9, 10], laser scanning [32, 33] and 3D contact profilometry [34].

The aim of this study was to measure adhesive remnants and enamel loss after debonding orthodontic molar tubes and additionally to compare One-Step Finisher and Polisher, Adhesive Residue Remover and tungsten carbide bur referring to their effectiveness and safety.

\section{Methods}

This study was found to be exempt from ethical approval (Ethical Committee of Pomeranian Medical University of Szczecin, Ref. No. KB-0012/09/01/2013). Informed verbal consent was obtained from all participants.

\section{Sample preparation}

Thirty human third molars free from carious lesions, extracted for orthodontic reasons from patients aged 1624 years were selected, based on the criterion of intact buccal surfaces free from cracks or restorations. They were stored in distilled water for $24 \mathrm{~h}$ before bonding, then cleaned using a low-speed bristle brush, rinsed for $10 \mathrm{~s}$ and dried with oil-free compressed air. For the purpose of 3D scanning, the experimental teeth were embedded in impression silicone (Bisico S1 Soft, Bisico, Germany) in order to prevent unnecessary movement during manipulation.

\section{Bonding, debonding and clean-up procedures}

Following a $20 \mathrm{~s}$ etching with $35 \%$ phosphoric acid (Ultra Etch, Ultradent, USA) molar tubes (ERA, Farfield, USA) were bonded directly, using chemical-cure orthodontic adhesive (Unite, 3M, USA), similarly to the clinical conditions: at the centre of each buccal surface, parallel to the long axis of the crown. The teeth with tubes bonded were then stored in $0.9 \%$ saline solution for $24 \mathrm{~h}$, rinsed with distilled water to prevent saline crystallization, dried with oil-free compressed air and debonded using ligature cutting pliers. The pliers were positioned similarly to in the clinical conditions, e.g. occlusally and gingivally in order to gently peel the tube from the enamel.

The clean up procedure was performed by the same operator under typical clinical conditions and continued until no macroscopically visible adhesive remnants could be found. Since macroscopic debonding patterns were different for individual molars, the authors decided not to assess the time needed to remove adhesive remnants. Three different tools were used for each set of ten specimens: a twelve-fluted tungsten carbide bur (123-603-00, Dentaurum, Pforzheim, Germany), a one-step finisher and polisher (inverted cone One gloss, Shofu Dental, Kyoto, Japan) and Adhesive Residue Remover (989-34260, Dentaurum, Pforzheim, Germany).

\section{Assessment of adhesive remnants and enamel loss}

All the specimens were scanned in blue-light technology, using a 3D optical scanner (Atos III, Triple Scan, GOM, Germany) before etching and after adhesive rest removal. Scanning was proceeded using a lens with a field of $170 \times 130 \times 130 \mathrm{~mm}$, to the nearest $2 \mu \mathrm{m}$. The high scanner precision was maintained by a regular calibration procedure, as indicated by the manufacturer, thus an error study was not necessary. Two cameras observed the course of stripes projected on the teeth and point coordination was calculated for each pixel of the camera sensor. Scans of initial enamel surfaces were used as reference and those after adhesive removal - as virtual objects. Shape alteration of the enamel surface of each tooth was calculated using GOM Inspect software (GOM, Braunschweig, Germany). This procedure allowed the calculation of adhesive remnant height and enamel loss depth in every location of the buccal surface. Subsequently, the volume of adhesive remnant remaining 


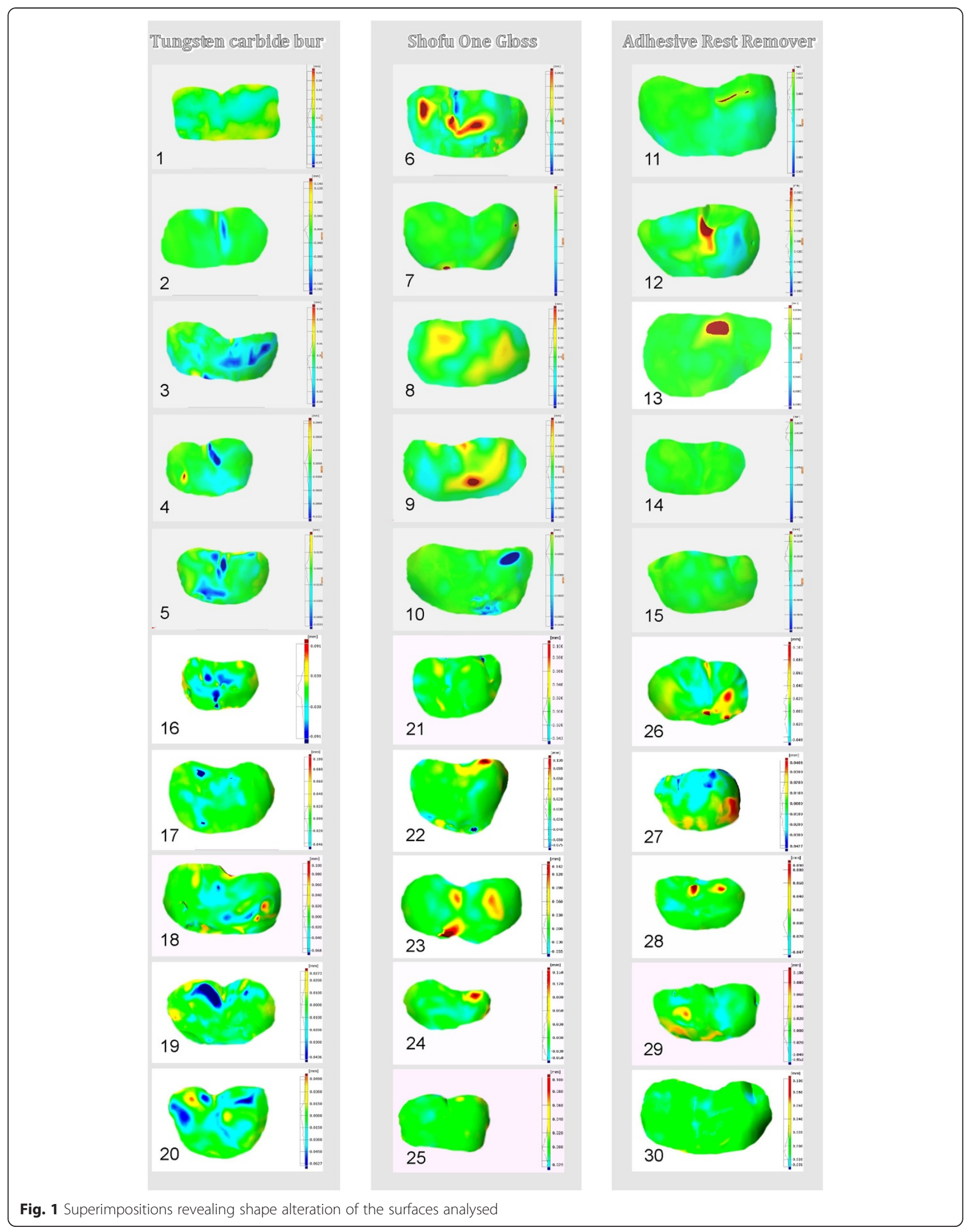


and the volume of enamel lost were calculated for each tooth.

\section{Proposed index and statistical analysis}

Data normality was tested using Shapiro-Wilk test at the level of significance $\alpha=0.05$. In order to compare variables between the groups of teeth, two tests were used at the level of significance of $\alpha=0.05$ : a parametric ANOVA test for data of normal distribution and nonparametric ANOVA rank Kruskal-Wallis test - for data which did not show distribution normality.

The tools used should remove maximum residual adhesive with minimal enamel loss, thus an index of effectiveness and safety was calculated for every tool, according to the following equation:

$$
I=\frac{V_{A}+2 V_{E}}{3}
$$

where $\mathrm{I}$ is a weighted average, $\mathrm{V}_{\mathrm{A}}$ is adhesive rest volume and $V_{E}$ is enamel loss volume; these are divided by a sum of multiplicands where enamel loss has been rated to be twice as harmful as adhesive remnants (enamel damage is irreversible and thus more detrimental).

Comparisons were made for adhesive remnant height and volume, for enamel loss depth and volume as well

Table 1 Adhesive remnants on particular teeth following adhesive removal

\begin{tabular}{|c|c|c|c|}
\hline \multirow[t]{3}{*}{ Tool } & \multicolumn{3}{|l|}{ Adhesive remnants } \\
\hline & \multicolumn{2}{|l|}{ Height [mm] } & \multirow{2}{*}{$\begin{array}{l}\text { Volume } \\
{\left[\mathrm{mm}^{3}\right]}\end{array}$} \\
\hline & Mean (SD) & Min-Max & \\
\hline \multirow[t]{10}{*}{ Tungsten carbide bur } & $0.005838(0.00471)$ & $0.000008-0.028$ & 0.079 \\
\hline & $0.015758(0.036838)$ & $0.000126-0.3649$ & 0.102 \\
\hline & $0.004727(0.003761)$ & $0.000077-0.0179$ & 0.0153 \\
\hline & $0.01428(0.019394)$ & $0.000044-0.1104$ & 0.065 \\
\hline & $0.006079(0.005262)$ & $0.000001-0.031$ & 0.032 \\
\hline & $0.015872(0.011378)$ & $0.000007-0.069$ & 0.302 \\
\hline & $0.009011(0.005749)$ & $0.000009-0.031$ & 0.1149 \\
\hline & $0.14768(0.014382)$ & $0.000061-0.1489$ & 0.3154 \\
\hline & $0.006993(0.005334)$ & $0.000038-0.02726$ & 0.0787 \\
\hline & $0.010139(0.008777)$ & $0.000007-0.049011$ & 0.07405 \\
\hline \multirow[t]{10}{*}{ Shofu One Gloss } & $0.012092(0.014155)$ & $0.000002-0.0814$ & 0.138 \\
\hline & 0.0153979 (0.0143199) & $0.000033-0.0744$ & 0.074 \\
\hline & $0.022308(0.016684)$ & $0.000058-0.0667$ & 0.229 \\
\hline & 0.0291329 (0.022995) & $0.00004-0.1101$ & 0.14 \\
\hline & $0.00712(0.005333)$ & $0.000005-0.0275$ & 0.084 \\
\hline & $0.008655(0.007351)$ & $0.000007-0.040891$ & 0.082445 \\
\hline & $0.0185389(0.020335)$ & $0.000027-0.148891$ & 0.26352 \\
\hline & $0.03885(0.046852)$ & $0.000011-0.223663$ & 0.3044 \\
\hline & $0.026101(0.02642)$ & $0.000106-0.172313$ & 0.232624 \\
\hline & $0.00771(0.006548)$ & $0.000003-0.03969$ & 0.12739 \\
\hline \multirow[t]{10}{*}{ Adhesive Residue Remover } & $0.006229(0.006331)$ & $0.000004-0.0307$ & 0.076 \\
\hline & $0.024641(0.038086)$ & $0.000002-0.2111$ & 0.281 \\
\hline & $0.008671(0.012583)$ & $0.000001-0.0633$ & 0.046 \\
\hline & $0.00461(0.003111)$ & $0.000005-0.0127$ & 0.05 \\
\hline & $0.008(0.005614)$ & $0.00006-0.0297$ & 0.087 \\
\hline & $0.027002(0.030753)$ & $0.000019-0.247408$ & 0.2213 \\
\hline & $0.010685(0.008191)$ & $0.000001-0.041085$ & 0.1413 \\
\hline & $0.015896(0.024687)$ & $0.000005-0.178489$ & 0.13467 \\
\hline & $0.013959(0.012721)$ & $0.000022-0.068929$ & 0.06608 \\
\hline & $0.007048(0.006245)$ & $0.000033-0.039596$ & 0.033121 \\
\hline
\end{tabular}


as for the proposed index of tool effectiveness and safety.

\section{Results}

Superimpositions revealing shape alteration of the analysed surfaces are presented in Fig. 1.

The results concerning adhesive remnants height and volume after orthodontic clean-up using three different tools have been presented in Table 1 .

No statistically significant differences in the volume $(p=0.35)$ or mean height $(p=0.24)$ of adhesive remnants were found (ANOVA rank Kruskal-Wallis test) between the groups of teeth cleaned using the various tools. Thus, the compared tools had a similar effectiveness. A superimposition of $3 \mathrm{D}$ scans made before bonding and those made after adhesive removal (Fig. 1.) suggests that adhesive remnants were left mainly in pits and fissures.

Enamel loss depth and volume resulting from orthodontic clean-up using three different tools have been presented in Table 2. Statistically significant differences (parametric ANOVA test) were found related to the volume of enamel loss $(F=2.816, p=0.0078)$, while the mean depths of enamel loss did not differ significantly $(p=0077)$. The most destructive tool was tungsten carbide bur and the least was Adhesive Residue Remover.

Table 2 Enamel loss on particular teeth after adhesive removal

\begin{tabular}{|c|c|c|c|}
\hline \multirow[t]{3}{*}{ Tool } & \multicolumn{3}{|l|}{ Enamel loss } \\
\hline & \multicolumn{2}{|l|}{ Depth [mm] } & \multirow{2}{*}{$\begin{array}{l}\text { Volume } \\
{\left[\mathrm{mm}^{3}\right]}\end{array}$} \\
\hline & Mean (SD) & Min - Max & \\
\hline \multirow[t]{10}{*}{ Tungsten carbide bur } & $0.005726(0.003982)$ & $0.000042-0.189$ & 0.158 \\
\hline & $0.0375016(0.05145)$ & $0.000012-0.3661$ & 3.92 \\
\hline & $0.00974(0.008096)$ & $0.000034-0.0631$ & 1.486 \\
\hline & $0.01076(0.009623)$ & $0.000002-0.0539$ & 3.55 \\
\hline & $0.01446(0.014448)$ & $0.000001-0.0923$ & 1.25 \\
\hline & $0.025638(0.02466)$ & $0.000011-0.1439$ & 2.998 \\
\hline & $0.0141(0.012199)$ & $0.000004-0.0727$ & 1.755 \\
\hline & $0.018288(0.013947)$ & $0.000006-0.0709$ & 1.994 \\
\hline & $0.011003(0.012159)$ & $0.000003-0.0767$ & 2.8412 \\
\hline & $0.018033(0.014741)$ & $0.000027-0.07849$ & 1.63595 \\
\hline \multirow[t]{10}{*}{ Shofu One Gloss } & $0.00838(0.00704)$ & $0.000009-0.0506$ & 0.636 \\
\hline & $0.013435(0.01055)$ & $0.000057-0.0635$ & 0.473 \\
\hline & $0.013494(0.007662)$ & $0.000079-0.0308$ & 0.18 \\
\hline & $0.017028(0.011577)$ & $0.000058-0.0484$ & 0.303 \\
\hline & $0.02347(0.038124)$ & $0.000011-0.2251$ & 2.99 \\
\hline & 0.009936 (0.011993) & $0.000009-0.12439$ & 3.577 \\
\hline & $0.016158(0.020371)$ & $0.000014-0.20527$ & 2.18648 \\
\hline & $0.013648(0.010161)$ & $0.000003-0.0554$ & 1.2456 \\
\hline & $0.018005(0.010717)$ & $0.000033-0.0495$ & 0.917376 \\
\hline & $0.007047(0.005541)$ & $0.000002-0.02898$ & 1.1427 \\
\hline \multirow[t]{10}{*}{ Adehsive Residue Remover } & $0.012473(0.007595)$ & $0.000005-0.0351$ & 0.5 \\
\hline & $0.006229(0.006331)$ & $0.000004-0.0694$ & 1.04 \\
\hline & $0.00417(0.0032)$ & $0.000025-0.0175$ & 0.109 \\
\hline & $0.00546(0.003323)$ & $0.000013-0.0158$ & 0.114 \\
\hline & 0.007599 (0.006932) & $0.000014-0.0375$ & 0.388 \\
\hline & 0.017349 (0.009953) & $0.000009-0.04798$ & 1.0587 \\
\hline & $0.0134014(0.008185)$ & $0.000009-0.04272$ & 0.5877 \\
\hline & $0.008962(0.007083)$ & $0.000003-0.04717$ & 1.53533 \\
\hline & $0.012287(0.009107)$ & $0.000034-0.07611$ & 0.60592 \\
\hline & $0.009388(0.005774)$ & $0.00001-0.03067$ & 0.646879 \\
\hline
\end{tabular}


Comparison (parametric ANOVA test) of the proposed new index I between the tools revealed highly statistically significant differences $(p=0.0081)$, supporting the best value for Adhesive Residue Remover and the worst - for tungsten carbide bur.

\section{Discussion}

Many studies evaluated adhesive remnants using Adhesive Remnant Index (ARI) [16, 17, 19, 21, 23, 35-40], however this surface assessment method does not allow the measurement of adhesive height or volume.

The present study investigated the cumulative effect of acid etching, debonding and adhesive removal. As the method of direct blue-light 3D scanning eliminates the reflections, the teeth can be scanned directly and there is no need for sputtering or making plaster models, resulting in higher accuracy. Most recently - this method was used to assess adhesive remnants and enamel loss after debonding molar tubes [41] and proved to be precise and reliable. In this study the authors used it to analyse the effect of grinding adhesive remnants.

This is the first study directly measuring adhesive remnants and enamel loss resulting from orthodontic cleanup. Moreover, this is the first study to assess the effect of adhesive removal with one step finisher and polisher as well as Adhesive Residue Remover.

Pont et al. [21] found no correlation between the amount of adhesive remnants and scoring of enamel surface after debonding and clean-up. Thus, no analysis of adhesive remnants before clean-up was presented in this study. However, adhesive remnant volume after debonding molar tubes has been presented elsewhere [41].

The amount of adhesive remnants after the clean up procedure depends on the operator, surface topography (fissures and porosity retain more adhesive) as well as on the tool used. It can be supposed that every tool may cut off the enamel especially in convex areas, causing enamel faceting, whereas remnant adhesive may be left in pits and fissures.

An elastic rotary instrument - a green rubber wheel has long been used for orthodontic adhesive removal by Gwinnet and Gorelick [4], who have concluded that it was the most effective (compared to green stone, white stone, sandpaper discs, tungsten carbide bur, steel bur or acrylic steel bur), giving a macroscopic polish; fine scratches were visible only microscopically and could easily be removed using pumice prophylaxis paste. It is interesting, that this tool, described as more efficient and less destructive than the most popular tungsten carbide burs has never been reported in any later studies.

It can be supposed that an elastic tool adapts its shape to the tooth surface, following the pits and fissures. Thus, prominent areas were ground less than by the tungsten carbide bur.
Rubber wheels may have different abrasive particles and different binders. One Gloss employs aluminium dioxide and silicone dioxide as an abrasive and the abrasive delivery medium is polyvinylsiloxane [42].

Adhesive Residue Remover is a stiff abrasive tool, with an appearance similar to a semi-transparent stone or rubber. No studies, which describe its use for orthodontic adhesive removal could be found. The first author contacted the manufacturer, asking for its composition, and was informed that this tool is made of epoxy resin and glass. We assume that epoxy resin is softer than enamel and while abraded, the abrasive particles of the tool are exposed. The detailed composition of the abrasive particles remains unknown, however it has been found that enamel loss is lower than for tungsten carbide bur or Shofu One Gloss.

It should be remembered, that a certain amount of adhesive is penetrating the etched enamel and this cannot be detected by surface scanning technique, constituting a possible limitation of this study.

Moreover, it should be noted, that enamel loss is one of the two aspects of iatrogenic enamel damage, e.g. removal of an enamel layer and enamel scratching (roughening).

\section{Conclusion}

It can be concluded that the compared tools had a similar effectiveness. Referring to enamel loss, tungsten carbide bur had the most destructive effect, and Adhesive Residue Removal was found to be the safest.

\section{Abbreviations}

3D: three-dimensional; ANOVA: analysis of variance; ARI: Adhesive Remnant Index; SEM: scanning electron microscope.

\section{Competing interests}

The authors declare that they have no competing interests.

Authors' contributions

JJO - study conception and design, data interpretation, writing manuscript. KT and TS - 3D scanning and data processing, participation in data interpretation. PS - statistical analysis and its interpretation. KST - providing material for the study (extracted teeth), participation in manuscript preparation. KG - critical revising for intellectual content. All authors have read and approved the final version of the manuscript.

\section{Authors' information}

$\mathrm{JJO}$ is a practising orthodontist and senior lecturer Department of General Dentistry. KT and TS are engineer scientists and assistant professors Faculty of Mechanical Engineering. PS is engineer scientist, associate professor Department of Technology and Education. KST is a practising specialist in both oral and maxillofacial surgery, head of Clinic of Maxillofacial Surgery. KG is a practising specialist in prosthetic dentistry, head of an interdisciplinary Department of General Dentistry.

\section{Acknowledgements}

The study has been founded by Pomeranian Medical University of Szczecin (grant FSN-275-03/13), which founded mathematical analysis of data from 3D scanning. 


\section{Author details}

'Department of General Dentistry Pomeranian Medical, University of Szczecin, Al. Powstancow Wlkp. 72, 70-111 Szczecin, Poland. Faculty of Mechanical Engineering Koszalin, University of Technology, ul. Raclawicka 15-17, 75-620 Koszalin, Poland. '3epartment of Technology and Education, ul. Śniadeckich 2, 75-453 Koszalin, Poland. ${ }^{4}$ Clinic of Maxillofacial Surgery Pomeranian Medical, University of Szczecin, Al. Powstancow Wlkp. 72, 70-111 Szczecin, Poland.

\section{Received: 2 March 2015 Accepted: 6 November 2015}

\section{Published online: 18 November 2015}

\section{References}

1. Zarrinnia K, Eid NM, Kehoe MJ. The effect of different debonding techniques on the enamel surface: an in vitro qualitative study. Am J Orthod Dentofac Orthop. 1995;108:284-93.

2. Campbell PM. Enamel surfaces after orthodontic bracket debonding. Angle Orthod. 1995;65:103-10.

3. Retief DH, Denys FR. Finishing of enamel surfaces after debonding of orthodontic attachments. Angle Orthod. 1979;49:1-10.

4. Gwinnett AJ, Gorelick L. Microscopic evaluation of enamel after debonding clinical application. Am J Orthod. 1977:71:651-65

5. Rouleau BD, Marshall Jr GW, Cooley R. Enamel surface evaluations after clinical treatment and removal of orthodontic brackets. Am J Orthod. 1982; 81:423-6.

6. David VA, Stanley RN, Bigelow HF, Jakobsen JR. Remnant amount and cleanup for 3 adhesives after debracketing. Am J Orthod Dentofac Orthop. 2002;121:291-6

7. Karan S, Kiircelli BH, Tasdelen B. Enamel surface roughness after debonding Comparison of two different burs. Angle Orthod. 2010;80:1081-8.

8. Kim SS, Park WK, Son WS, Ahn HS, Ro JH, Kim YD. Enamel surface evaluation after removal of orthodontic composite remnants by intraoral sandblasting: a 3-dimensional surface profilometry study. Am J Orthod Dentofac Orthop. 2007;132:71-6.

9. Hosein I, Sherriff M, Ireland AJ. Enamel loss during bonding, debonding and cleanup with use of a self-etching primer. Am J Orthod Dentofac Orthop. 2004:126:717-24.

10. Ireland AJ, Hosein I, Sherriff M. Enamel loss at bond-up, debond and clean- up following the use of a conventional light-cured composite and a resin- modified glass polyalkenoate cement. Eur J Orthod. 2005; 27:413-9.

11. Janiszewska-Olszowska J, Szatkiewicz T, Tomkowski R, Tandecka K Grocholewicz K. Effect of orthodontic debonding and adhesive removal on the enamel - current knowledge and future perspectives - a systematic review. Med Sci Monit. 2014;20:1991-2001.

12. Ulusoy C. Comparison of finishing and polishing systems for residual resin removal after debonding. J Appl Oral Sci. 2009;17:209-15.

13. Eminkahyagil N, Arman A, Cetinşahin A, Karabulut E. Effect of resin-removal methods on enamel and shear bond strength of rebonded brackets. Angle Orthod. 2006;76:314-21.

14. Radlanski RJ. A new carbide finishing bur for bracket debonding. J Orofac Orthop. 2001;62:296-304.

15. Smith SC, Walsh $\sqcup$, Taverne AA. Removal of orthodontic bonding resin residues by CO2 laser radiation: surface effects. J Clin Laser Med Surg. 1999;17:13-8.

16. Osorio R, Toledano M, Garcia-Godoy F. Enamel surface morphology after bracket debonding. ASDC J Dent Child. 1998;65:313-7.

17. Sessa T, Civović J, Pajević T, Juloski J, Beloica M, Pavlović V, et al. Scanning electron microscopic examination of enamel surface after fixed orthodontic treatment: in-vivo study. Srpski Celok Lek. 2012;140:22-8.

18. Baumann DF, Brauchli $L$, van Vaes $H$. The influence of dental loupes on the quality of adhesive removal in orthodontic debonding. J Orofac Orthop. 2011;201:125-32.

19. Alessandri Bonetti G, Zanarini M, Incerti Parenti S, Latucca M, Marchionni S, Gatto MR. Evaluation of enamel surfaces after bracket debonding: an in-vivo study with scanning electron microscopy. Am J Orthod Dentofac Orthop. 2011:140:696-702.

20. Schiefelbein C, Rowland K. A comparative method of adhesive removal methods. Int J Orthod Milnawaukee. 2011;22:17-22

21. Pont HB, Özcan M, Bagis B, Ren Y. Loss of surface enamel after bracket debonding: an in-vivo and ex-vivo evaluation. Am J Orthod Dentofac Orthop. 2010;138(387):e1-9. discussion 387-389.
22. Almeida HC, Vedovello Filho M, Vedovello SA, Young AA, Ramirez-Yanez GO. Enamel surface after debracketing of orthodontic brackets bonded with flowable orthodontic composite. A comparison with a traditional orthodontic composite resin. Int J Orthod Milnawaukee. 2009:20:9-13.

23. Tecco S, Tetè S, D'Attilio M, Festa F. Enamel surface after debracketing of orthodontic brackets bonded with flowable orthodontic composite. A comparison with a traditional orthodontic composite resin. Minerva Stomatol. 2008;57:81-94.

24. Roush EL, Marshall SD, Forbes DP, Perry FU. In vitro study assessing enamel surface roughness subsequent to various final finishing procedures after debonding. Northwestern Dent Res. 1977;7:2-6.

25. Eliades T, Gioka C, Eliades G, Makou M. Enamel surface roughness following debonding using two resin grinding methods. Eur J Orthod. 2004;26:333-8.

26. Ahrari F, Akbari M, Akbari J, Dabiri G. Enamel surface roughness after debonding of orthodontic brackets and various clean-up techniques. J Dent (Tehran). 2013;10:82-93.

27. Ferreira FG, Nouer DF, Silva NP, Garbui IU, Correr-Sobrinho L, Nouer PR Qualitative and quantitative evaluation of human dental enamel after bracket debonding: a noncontact three-dimensional optical profilometry analysis. Clin Oral Investig. 2014;18:1853-64.

28. Fitzpatrick DA, Way D. The effects of wear, acid etching and bond removal on human enamel. Am J Orthod. 1977:72:671-81.

29. Brown CRL, Way D. Enamel loss during orthodontic bonding and subsequent loss during removal of filled and unfilled adhesives. Am J Orthod. 1978;74:663-71.

30. Pus MD, Way D. Enamel loss due to orthodontic bonding with filled and unfilled resins using various clean-up techniques. Am J Orthod. 1980;77: 269-83.

31. Tüfekçi $E$, Merrill TE, Pintado MR, Beyer JP, Brantley WA. Enamel loss associated with orthodontic adhesive removal on teeth with white spot lesions: an in vitro study. Am J Orthod Dentofac Orthop. 2004;125:733-9.

32. Al Shamsi AH, Cunningham JL, Lamey PJ, Lynch E. Three-dimensional measurement of residual adhesive and enamel loss on teeth after debonding of orthodontic brackets: an in-vitro study. Am J Orthod Dentofac Orthop. 2007; 131:301. e9-15.

33. Ryf S, Flury S, Palaniappan S, Lussi A, van Meerbeek B, Zimmerli B. Enamel loss and adhesive remnants following bracket removal and various clean-up procedures in vitro. Eur J Orthod. 2012;34:25-32.

34. Banerjee A, Paolinelis G, Socker M, McDonald F, Watson TF. An in vitro investigation of the effectiveness of bioactive glass air-abrasion in the 'selective' removal of orthodontic resin adhesive. Eur J Oral Sci. 2008;116: 488-92.

35. Osorio R, Toledano M, Garcia-Godoy F. Bracket bonding with 15- or 60-second etching and adhesive remaining on enamel after debonding. Angle Orthod. 1999;69:45-8

36. Eslamian L, Borzabadi-Farahani A, Mousavi N, Ghasemi A. A comparative study of shear bond strength between metal and ceramic brackets and artificially aged composite restorations using different surface treatments. Eur J Orthod. 2012;34:610-7.

37. Kinch AP, Taylor H, Warltier R, Oliver RG, Newcombe RG. A clinical study of amount of adhesive remaining on enamel after debonding, comparing etch times of 15 and 60 seconds. Am J Orthod Dentofacial Orthop. 1989:95:415-21.

38. Knosel M, Mattysek S, Jung K, Sadat-Khonsari R, Kubein-Meesenburg D, Bauss $\mathrm{O}$, et al. Impulse debracketing compared to conventional debonding. Angle Orthod. 2010;80:1036-44.

39. Eslamian L, Borzabadi-Farahani A, Tavakol P, Tavakol A, Amini N, Lynch E. Effect of multiple debonding sequences on shear bond strength of new stainless steel brackets. J Orthod Sci. 2015;4(2):37-41. doi:10.4103/2278-0203. 156027.

40. Brosh T, Kaufman A, Balabanovsky A, Vardimon AD. In vivo strength and enamel damage in two orthodontic debonding methods. J Biomech. 2005; 38:1107-13

41. Janiszewska-Olszowska J, Tandecka K, Szatkiewicz T, Sporniak-Tutak K, Grocholewicz K. Three-dimensional quantitative analysis of adhesive remnants and enamel loss resulting from debonding orthodontic molar tubes. Head Face Med. 2014;10:37.

42. Yap AU, Yap SH, Teo CK, Nq JJ. Finishing/polishing of composite and compomer restoratives: effectiveness of one-step systems. Oper Dent. 2004; 29:275-9. 